\title{
CURRENT RESEARCH ON OPTICAL MATERIALS, DEVICES AND SYSTEMS IN TAIWAN
}


SELECTED TOPICS IN ELECTRONICS AND SYSTEMS

Editor-in-Chief: P. K. Tien

Published

Vol. 1: Current Trends in Integrated Optoelectronics ed. T. P. Lee

Vol. 2: Current Trends in Heterojunction Bipolar Transistors ed. M. F. Chang

Vol. 3: Current Trends in Vertical Cavity Surface Emitting Lasers ed. T. P. Lee

Vol. 4: Compound Semiconductor Electronics: The Age of Maturity ed. M. Shur

Vol. 5: High Performance Design Automation for Multichip Modules and Packages ed. J. Cho and co-ed. P. D. Franzon

Vol. 6: Low Power VLSI Design and Technology eds. G. Yeap and F. Najm

Vol. 7: Current Trends in Optical Amplifiers and Their Applications ed. T. P. Lee

Vol. 8: Current Research and Developments in Optical Fiber Communications in China eds. Q. -M. Wang and T. P. Lee

Vol. 9: Signal Compression: Coding of Speech, Audio, Text, Image and Video ed. N. Jayant

Vol. 10: Emerging Optoelectronic Technologies and Applications ed. Yu-Hwa Lo

Vol. 11: High Speed Semiconductor Lasers ed. S. A. Gurevich

\section{Forthcoming}

Vol. 13: High Speed Circuits for Lightwave Communications ed. K.-C. Wang 


\section{CURRENT RESEARCH \\ ON OPTICAL MATERIALS, \\ DEVICES AND SYSTEMS \\ IN TAIWAN}

Editors

\section{S. Chi}

National Chiao Tung University,

Taiwan

T. P. Lee

National Science Foundation, USA 
Published by

World Scientific Publishing Co. Pte. Ltd.

P O Box 128, Farrer Road, Singapore 912805

USA office: Suite 1B, 1060 Main Street, River Edge, NJ 07661

UK office: 57 Shelton Street, Covent Garden, London WC2H 9HE

\section{British Library Cataloguing-in-Publication Data}

A catalogue record for this book is available from the British Library.

\section{CURRENT RESEARCH ON OPTICAL MATERIALS, DEVICES AND SYSTEMS IN TAIWAN}

Copyright $\odot 1998$ by World Scientific Publishing Co. Pte. Ltd.

All rights reserved. This book, or parts thereof, may not be reproduced in any form or by any means, electronic or mechanical, including photocopying, recording or any information storage and retrieval system now known or to be invented, without written permission from the Publisher.

For photocopying of material in this volume, please pay a copying fee through the Copyright Clearance Center, Inc., 222 Rosewood Drive, Danvers, MA 01923, USA. In this case permission to photocopy is not required from the publisher.

ISBN 981-02-3297-7

Printed in Singapore by Uto-Print 


\section{INTRODUCTION}

During the last quarter of a century, the economy in Taiwan has transformed from a basically agricultural economy into an industrial one. Consumer electronics and personal computers have replaced rice and textiles as the leading export products. The people in Taiwan have enjoyed a standard of living that is unprecedented in Chinese history. The success of the industrialization in Taiwan can be attributed to a combination of factors: a sound government policy, a dynamical local industry, and, to a large extent, a well-educated and motivated work force.

Since the mid-1980's, the electronics industry in Taiwan has shifted its emphasis from customer-based electronics to information-based electronics products. Taiwan is now enjoying $65 \%$ of the world market for PC motherboards and keyboards, $64 \%$ in scanners, and $57 \%$ in PC-monitors. The electronic information products amount to $46 \%$ of the electronics exports at a total value of $\$ 35$ billion in 1995 .

Among information-based electronics, a sub-group in optoelectronics is starting to grow. In addition to the PC-monitors and the visible light-emitting diodes for displays that have already established a large world market share, other technologies such as optical storage, optical signal processing, optical switching and transmission are emerging. Focused research efforts in various universities and research institutions are strongly supported by the National Science Council, the Ministry of Economic Affairs, and the Ministry of Telecommunications.

A Photonic/Taiwan'96 Seminar was held on December 12-13, 1996, in the Industrial Techology Research Institute in Hsinchu, Taiwan. The seminar was cosponsored by the Optical Engineering Society of the Republic of China, IEEE/LEOS Taipei Chapter, SPIE Taiwan Chapter, and the National Science Council. A total of 166 technical papers were presented that encompassed broad subject areas which included:

(1) group III-IV semiconductor materials including nitrides,

(2) organic materials and optical thin films,

(3) semiconductor lasers and optical amplifiers,

(4) photodetectors and photodiode arrays,

(5) optical fiber communications,

(6) optical measurements,

(7) optical pattern recognition and signal processing,

(8) optical computing,

(9) nonlinear optics and optical memory,

(10) guided-wave optical devices,

(11) display technology, 
(12) optical storage devices,

(13) ultra-fast optics, and

(14) solid-state lasers.

Prof. Sien Chi, the guest editor, has invited authors who have participated in the seminar mentioned above to contribute to this volume. He has selected subject areas that are representative to that covered in the seminar. The first two papers deal with epitaxial growth in InP and InGaAs multiple quantum wells by MOCVD and MBE techniques respectively. A high quality InP epitaxial layer that was obtained by using flow-rate-modulation MOCVD is reported by $\mathrm{M}$. K. Lee, and a large absorption edge shift, that was observed in the MBE-grown InGaAs MQW at 1.3 micron wavelength, is presented by C. T. Lee and T. E. Nee. In the third paper, C. C. Yang et al., present a comprehensive view of passive mode-locking techniques of lasers. A mode-locked laser produces very short optical pulses that are essential for very high-speed time-division-multiplexed optical systems such as soliton communication systems. Numerical simulations of a nonlinear polarization mode-locked laser, a nonlinear coupling mode-locked semiconductor laser and an additive-pulse mode-locked fiber laser are also discussed. The following three papers deal with guided-wave devices. Y. T. Huang et al. discussed dual antiresonant reflecting optical waveguide (ARROW) devices in both $\mathrm{SiO}_{2} / \mathrm{TiO}_{2}$ and $\mathrm{InP} / \mathrm{InGaAsP}$ systems. The ARROW concept can be applied to power dividers, hybrid couplers, wavelength filters, polarization beamsplitters, and pressure sensors. W. S. Wang, Y. P. Liao and C. H. Yang introduce a nickle-indiffusion waveguide for the TE-TM mode splitter in lithium niobate, and show improved performance with a much simplified process. A numerical analysis of nonlinear directional couplers is presented by C. H. Lai, H. C. Chang, and J. P. Pang using the segmentation method that produced more accurate results compared with the simple coupled-mede theory and its improved version. In the seventh paper, a theoretical model of a quantum-mechanical energy band filter with resonant semiconductor superlattices is presented by $\mathrm{H}$. H. Tung and C. P. Lee. The analysis uses a quantum-mechanical wave impedance (QMWI) matching method that is analogous to the familiar circuit theory. Based on the QMWI method a structure for a perfect energy pass-band filter is proposed. The method is also used to analyze the scattering process in a resonant tunneling diode. The eighth paper, presented by Y. K. Su and C. T. Lin, discussed the performance of $\mathrm{HgCdTe}$ photoconductors with a simple photo surface treatment to reduce the $1 / f$ noise. A surface recombination velocity as low as $300 \mathrm{~cm} / \mathrm{sec}$ and a detectivity as sensitive as $3 \times 10^{10} \mathrm{cmHz}^{1 / 2} / \mathrm{W}$ have been obtained.

In the ninth paper, C. L. Pan et al. demonstrated an accurate, non-contact and compact electro-optical characterization technique for measuring both the amplitude and the phase of microwave standing waves in a GaAs microstrip transmission line. The voltage standing wave ratio and the reflection coefficient as well as the dispersion characteristics were determined up to $16 \mathrm{GHz}$. A general review of the real-time shift-invariant optical pattern recognition is given by $\mathrm{Y}$. S. Cheng in the 
tenth paper. In the eleventh paper, a read-only holographic memory for digital data storage is experimentally demonstrated by C. P. Yang et al. The performance of the memory and the techniques for improving its bit error rate are presented. Finally the last paper by Y. K. Chen, S. K. Liaw, and S. Chi described an experiment of a high-speed SONET wavelength-division-multiplexing self-healing ring network using optical power limiting amplifiers. A constant channel power, a small inter-channel power variation and a low noise figure with a large dynamic range are achieved.

This volume of collected papers by no means covers the breath and depth of the optical research that has been carried out in Taiwan; it simply represents a snap shot of a small sample of the work that is in progress. Evidently, some of the research results will lead to further development for commercial products that will be successful in the marketplace in the near future.

We are most grateful to the authors of this volume who have committed a good deal of their time and effort. We would also like to thank Dr. P. K. Tien, the Editorin-Chief of IJHSES, for his suggestions, enthusiasm, encouragement, and patience. Sincere thanks also go to the editorial staff of World Scientific Publishing Co. for the resourceful support throughout the preparation of this volume.

\author{
Sien Chi \\ Professor \\ Institute of Electro-Optical Engineering \\ National Chiao Tung University \\ Hsinchu, Taiwan \\ R.O.C. \\ Tien Pei Lee* \\ Chief Scientist and Director \\ Optoelectronic Technology Research \\ Bell Communications Research (Bellcore) \\ Red Bank, New Jersey 07701-5699 \\ U.S.A.
}

\footnotetext{
${ }^{*}$ Dr. Lee retired from Bellcore in February 1997. He is currently the Program Director at the National Science Foundation, Arlington, Virginia.
} 


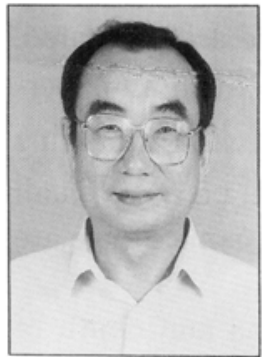

Sien Chi was born on July 6, 1936, in Huaiying, Jiangsu, China. He received a B.S.E.E. degree from National Taiwan University and an M.S.E.E. degree from National Chiao Tung University, Taiwan, ROC, in 1959 and 1961, respectively. He obtained his Ph.D. degree in electrophysics from the Polytechnic Institute of Brooklyn, Brooklyn, NY, in 1971.

In 1971, he joined the faculty of National Chiao Tung University, where he is currently a Professor of Electro-Optical Engineering. From 1972 to 1973, he was the Chairman of the Department of Electrophysics. From 1973 to 1977 , he was the Director of the Institute of Electronics. From 1977 to 1978, he was a resident visitor at Bell Laboratories, Holmdel, NJ. From 1985 to 1988, he was the Principal Advisor of Hua-Eng Wires and Cables Company, the first manufacturer of fibers and fiber cables in Taiwan, for developing fiber making and cabling technology. From 1988 to 1990, he was the Director of the Institute of Electro-Optical Engineering.

He is a Fellow of the Optical Society of America and the Photonics Society of ChineseAmericans. He was the Symposium Chair of the International Symposium on Optoelectronics in Computers, Communications and Control 1992, which was co-organized by National Chiao Tung University and SPIE. From 1993 he has been a recipient of the distinguished Research Award sponsored by the National Science Council, ROC. His research interests are in the area of optical solitons, optical fiber amplifiers and nonlinear fiber optics.

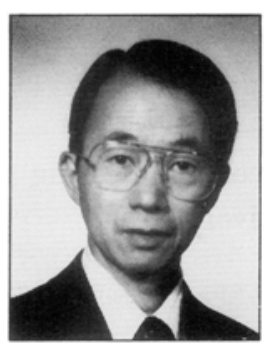

Dr. Tien Pei Lee is presently the Program Director of the National Science Foundation, in Arlington, Virginia. He was the Chief Scientist and the Director, Optoelectronic Technology Research, Bell Communications Research (Bellcore), Red Bank, New Jersey. He has published more than 200 technical articles and 10 book chapters on LEDs, photodiodes, and semiconductor lasers for optical fiber communications. He holds seven US patents and five foreign patents. Dr. Lee is the recipient of the Distinguished Member of Technical Staff Award, Bell Laboratories, 1983. He is a Fellow of IEEE, the Optical Society of America, and the Photonic Society of Chinese Americans. He served as the Guest Editor, IEEE Transactions on Electron Devices, April 1983, and the Associate Editor of the IEEE Journal of Lightwave Technology, 1986-88. He is now the Co-Editor-in-Chief of the International Journal of High Speed Electronics and Systems. 


\section{CONTENTS}

Introduction

High Quality InP Epitaxial Growth Using Flow Rate Modulation

Metalorganic Chemical Vapor Deposition

M. K. Lee and C. C. Hu

Electroabsorption of Unstrained InGaAs/InAlGaAs Multiple Quantum

Well Structure Grown on GaAs Substrates

C.-T. Lee and T.-E. Nee

Passive Mode-Locking Techniques of Lasers

C. C. Yang, D.-W. Huang, C.-W. Hsu, S.-Y. Liang, C.-W. Lay, and $M .-S$. Lin

Nickel-Indiffusion Waveguide for TE-TM Mode Splitter in Lithium Niobate W.-S. Wang, Y.-P. Liao, and C.-H. Yang

Dual Antiresonant Reflecting Optical Waveguide Devices

Y.-T. Huang, J. -J. Deng, Y.-H. Chen, C.-H. Jang, and C.-L. Wang

Numerical Analysis of Nonlinear Directional Couplers

C.-H. Lai, H.-C. Chang, and J.-P. Pang

Quantum-Mechanical Calculations of Resonant Semiconductor Devices:

A QMWI Approach

H.-H. Tung and C.-P. Lee

The Performance of $\mathrm{Hg}_{0.8} \mathrm{Cd}_{0.2}$ Te Photodetectors by Using Photo

Surface Treatment

Y. K. Su and C. T. Lin

Electro-Optic Characterization of Microwave Standing Waves in a

GaAs Transmission Line by Using a Novel Phase Analyzing Technique

C.-L. Pan, G.-R. Lin, J.-M. Shieh, C.-W. Tsai, S.-C. Wang, and H.-H. Wu 
Real-Time Shift-Invariant Optical Pattern Recognition Y.-S. Cheng

A Holographic Memory for Digital Data Storage C. P. Yang, S. H. Lin, M. L. Hsieh, K. Y. Hsu, and T. C. Hsieh

Investigation of Multiwavelength Optical Power Limiting Amplifier and its Applications in High-Speed SONET Wavelength-Division Multiplexing Self-Healing Ring Network

Y.-K. Chen, S.-K. Liaw, and S. Chi 